\title{
Sex hormone receptor expression and survival in esophageal adenocarcinoma: a prospective cohort study
}

\author{
Úna C. McMenamin ${ }^{1}$, James Trainor ${ }^{2}$, Helen G. Coleman ${ }^{5}$, Damian T. McManus' ${ }^{2}$, \\ Stephen McQuaid ${ }^{3}$, Victoria Bingham ${ }^{3}$, Jacqueline James $^{3}$, Manuel Salto-Tellez ${ }^{3}$, \\ Brian T. Johnston ${ }^{4}$ and Richard C. Turkington ${ }^{5}$ \\ ${ }^{1}$ Cancer Epidemiology Research Group, Centre for Public Health, Queen's University Belfast, Belfast, Northern Ireland, UK \\ ${ }^{2}$ Department of Pathology, Belfast Health and Social Care Trust, Belfast, Northern Ireland, UK \\ ${ }^{3}$ Northern Ireland Molecular Pathology Laboratory, Centre for Cancer Research and Cell Biology, Queen's University Belfast, \\ Belfast, Northern Ireland, UK \\ ${ }^{4}$ Department of Gastroenterology, Royal Victoria Hospital, Belfast Health and Social Care Trust, Belfast, Northern Ireland, UK \\ ${ }^{5}$ Centre for Cancer Research and Cell Biology, Queen's University Belfast, Belfast, Northern Ireland, UK \\ Correspondence to: Úna C. McMenamin, email: u.mcmenamin@qub.ac.uk \\ Keywords: estrogen receptor; androgen receptor; esophageal adenocarcinoma; survival; recurrence
}

Received: June 18, $2018 \quad$ Accepted: October 06, $2018 \quad$ Published: October 19, 2018

Copyright: McMenamin et al. This is an open-access article distributed under the terms of the Creative Commons Attribution License 3.0 (CC BY 3.0), which permits unrestricted use, distribution, and reproduction in any medium, provided the original author and source are credited.

\section{ABSTRACT}

Introduction: A striking epidemiological feature of esophageal adenocarcinoma (EAC) is its strong, unexplained male predominance but few studies have evaluated the prevalence of sex hormone receptor expression in EAC.

Results: A low proportion of EAC tumors stained positive for ERa (4\%) and AR (3\%) while approximately one third stained positive for ERß (31\%). After a mean follow-up of 3 years ( $\max 9$ years), no significant associations were seen for ERa, ERß or AR expression and EAC recurrence or survival. A non-significant reduction in mortality was observed for positive ER $\beta$ tumor expression, when restricting to patients with gastro-esophageal junctional (GEJ) cancer (HR 0.58, 95\% CI 0.33, 1.03, $p=0.06$ ).

Materials and Methods: We identified all EAC patients who underwent neoadjuvant chemotherapy prior to surgical resection between 2004-2012 in the Northern Ireland Cancer Centre. Immunohistochemical expression of ERa, ERß and AR was scored on triplicate cores to generate $\mathrm{H}$-scores. Cox proportional hazards regression was used to evaluate the association between sex hormone receptor expression and overall, cancer-specific and recurrence-free survival.

Conclusion: We found little evidence of ERa or AR expression in EAC. A moderate proportion expressed ER $\beta$ and there was suggestive evidence that its expression was associated with improved survival in GEJ cancer patients.

\section{INTRODUCTION}

The incidence of esophageal adenocarcinoma $(\mathrm{EAC})$ is rising and prognosis remains poor $[1,2]$. Despite advances in oncological and surgical management the five-year survival rate for EAC is only $15 \%$, and even in early localized disease treated with peri-operative chemotherapy, survival is less than $40 \%[3,4]$. Attempts to improve prognosis have focused on the surveillance of Barrett's esophagus, the precursor to EAC, but only a small proportion of patients have a previous Barrett's diagnosis $[5,6]$. The most striking epidemiological feature of EAC is its strong unexplained male predominance [7-9], with male-to-female incidence ratios of up to $6: 1$ observed $[10,11]$. This has led to the suggestion of sex hormone involvement in EAC development, possibly via estrogenic protection, a detrimental effect of androgens, or both $[12,13]$. 
Recent epidemiological evidence demonstrates associations between circulating sex steroid hormones and EAC risk [14]. Moreover, prognosis after surgical resection of EAC has been shown to be better in females compared to males $[15,16]$. Mounting preclinical evidence supports the hypothesis that sex hormones may be important in EAC pathogenesis [7]. Estrogens decrease tumor growth and increase apoptosis in EAC cell lines [17], while estrogen replacement has been shown to suppress esophageal damage of reflux esophagitis in animal models [18] and reduce esophageal tumor growth [19]. Androgen receptor (AR) is a key mediator of inflammatory signals in esophageal cancer progression and its expression has been shown to promote cell migration, invasion and proliferation in esophageal cancer in vivo $[13,20]$.

Although the exact mechanisms underlying sex hormone involvement in esophageal carcinogenesis remain unclear, it is potentially mediated through sex hormone receptors including estrogen receptors (ER) and AR [21]. $E R \alpha$ is predominantly expressed in female sex organs including the breast, uterus and ovaries while ER $\beta$ is widely expressed in many other tissues, including the esophagus, in both males and females [13, 22]. Other sex hormone receptors include the progesterone receptor, activated by the steroid hormone progesterone, and related receptors include G protein-coupled estrogen receptors (GPER), such as G protein-coupled estrogen receptor 1 or GPR30, which exert their physiological effects through ER $\alpha$ and $\beta$ via pregenomic pathways [23]. Clinical studies have shown complex patterns of ER expression in EAC specifically but few studies have been conducted and to date they have been small in size (e.g. 11-28 cases) [24-28]. Similarly, few studies have investigated AR expression in EAC tissue $[27,29,30]$. The association between sex hormone receptor expression and EAC prognosis has also received little attention; one study reported an inverse association between ER $\beta$ expression and cancer-specific survival [24] while another observed no association between AR expression and overall survival [30].

Considering that ER and AR signalling can be modulated through existing therapeutic selective targeting (in addition to emerging novel techniques such as selective ER $\beta$ agonists), further understanding of the role of sex hormone receptors in EAC is important considering that moleculartargeted intervention may offer opportunities for primary and secondary prevention. In a UK cohort study, we aimed to determine prevalence of $\mathrm{ER} \alpha, \mathrm{ER} \beta$ and $\mathrm{AR}$ expression in EAC tissue, and to investigate the influence of sex hormone receptor expression on EAC recurrence and survival.

\section{RESULTS}

\section{Patient cohort}

During the study period, a total of 158 formalinfixed paraffin embedded (FFPE) EAC resection specimens were collected from the Northern Ireland Cancer Centre. Clinical information was available for 154 of these patients. Four patients were excluded on the basis of complete pathological response (ypT0) following neoadjuvant chemotherapy, in addition to one patient who had metastases present at the time of surgery. Patients were additionally excluded if they lacked sufficient tumor within cores for immunohistochemical scoring leaving a total of 139, 138 and 138 in analysis of ER $\alpha, E R \beta$ and AR, respectively, see Figure 1. The majority of included patients were male $(78 \%)$ and average age at EAC diagnosis was 63 years. Most patients had tumors located in the gastro-esophageal junctional (GEJ) (83\%).

Patient characteristics by sex hormone receptor status are listed in Table 1. Although the prevalence of positive sex hormone receptor expression did not significantly differ by sex, the majority of ER $\alpha$ and ER $\beta$ positive expression was in male EAC patients ( $83.3 \%$ and $79.1 \%$, respectively), while positive expression of AR was only observed in males, see Figure 2.

Although only a minority of tumors expressed $E R \alpha$, patients whose tumors expressed ER $\alpha$ were more likely to have three or more disease positive nodes (i.e. at least ypN2 disease) compared to patients with negative expression. Demographic and lifestyle factors did not differ significantly according to sex hormone receptor status and similarly, there were no significant differences in tumor characteristics by ER $\alpha, \mathrm{ER} \beta$ or AR expression (Table 1). Average duration of follow-up was 3 years and ranged from 4 months to 9 years.

\section{Sex hormone receptor expression}

Figure $3 \mathrm{~A}-3 \mathrm{C}$ shows the immunohistochemical cellular staining according to positive and negative ER $\alpha$ expression. A low proportion of positive (nuclear) ER $\alpha$ staining was observed in 6 out of 139 patients (4.3\%), Figure $3 \mathrm{~A}$. A moderate proportion of EAC tumors were found to positively express ER $\beta$, which was predominantly nuclear in nature (43 out of 138 patients (31\%)) (Figure 3B). A small proportion of EAC tumors were positive for AR nuclear expression (4 out of $138(2.9 \%)$ ) (Figure 3C). Overall, the observed staining was largely homogenous in nature.

\section{ERa expression and EAC progression}

During follow-up, 86 cancer recurrences, 78 EACspecific deaths and 83 deaths from any cause occurred. Results for ER $\alpha$ expression and associated risk of EAC clinical outcomes are listed in Table 2. Unadjusted analysis did not demonstrate any significant associations between ER $\alpha$ expression and risk of cancer recurrence, cancer-specific or overall survival and results were similar following adjustment for potential confounders (HR 1.32, 95\% CI $0.41,4.24)$, (HR 1.14, 95\% CI $0.29,4.50)$ and (HR 1.36, 95\% CI 0.44, 4.23), respectively. 


\section{ERß expression and EAC progression}

In analysis of ER $\beta$ expression, a total of 87 recurrences, 79 cancer-specific deaths and 84 deaths from any cause were observed during follow-up. In adjusted analyses, improvements in overall survival (HR $0.71,95 \%$ CI $0.41,1.21$ ), cancer-specific survival (HR $0.73,95 \%$ CI $0.42,1.28$ ) and recurrence-free survival (HR 0.89, 95\% CI 0.53, 1.48) were observed for patients whose tumors expressed ER $\beta$ compared to those whose tumors were negative for $\mathrm{ER} \beta$, however results were not statistically significant.

\section{$A R$ expression and EAC progression}

In analysis of AR expression, there were 86 cancer recurrences, 78 deaths from EAC and 83 deaths from any cause identified during follow-up. No significant associations were observed for AR positive expression and risk of EAC outcomes, Table 2. Although HRs were raised in unadjusted analysis, they attenuated following adjustment for potential confounders and remained non-significant; overall survival (adjusted HR 1.50, 95\% CI 0.49, 4.62), cancer-specific survival (HR 1.48, 95\% CI 0.48, 4.55) and recurrence-free survival (HR 1.50, 95\% CI 0.49, 4.57).

\section{Sensitivity analysis}

Table 3 presents the results of sensitivity analyses restricting the cohort to patients diagnosed with tumors located in the GEJ. Overall, results were similar to the main analysis with no significant associations observed for $\mathrm{ER} \alpha$ or AR expression and risk of any outcome following adjustment for potential confounders. ER $\beta$ expression was associated with a reduced risk of death from any cause (HR 0.58, 95\% CI 0.33, 1.03, $p=0.06$ ) and reduced cancer-specific mortality (HR 0.59, 95\% CI 0.32, 1.07 , $p=0.08$ ), although results failed to reach statistical significance. A less marked (non-significant) association was seen for ER $\beta$ expression and recurrence-free survival (HR 0.75, 95\% CI 0.43, 1.29).

\section{DISCUSSION}

In a population-representative study of EAC patients who underwent neoadjuvant chemotherapy prior to surgical resection, we found little evidence of ER $\alpha$ or AR expression in EAC while expression of ER $\beta$ was identified in approximately one third of tumors. No significant associations were observed between ER $\alpha, E R \beta$ or AR expression and overall, cancer-specific or recurrence-free

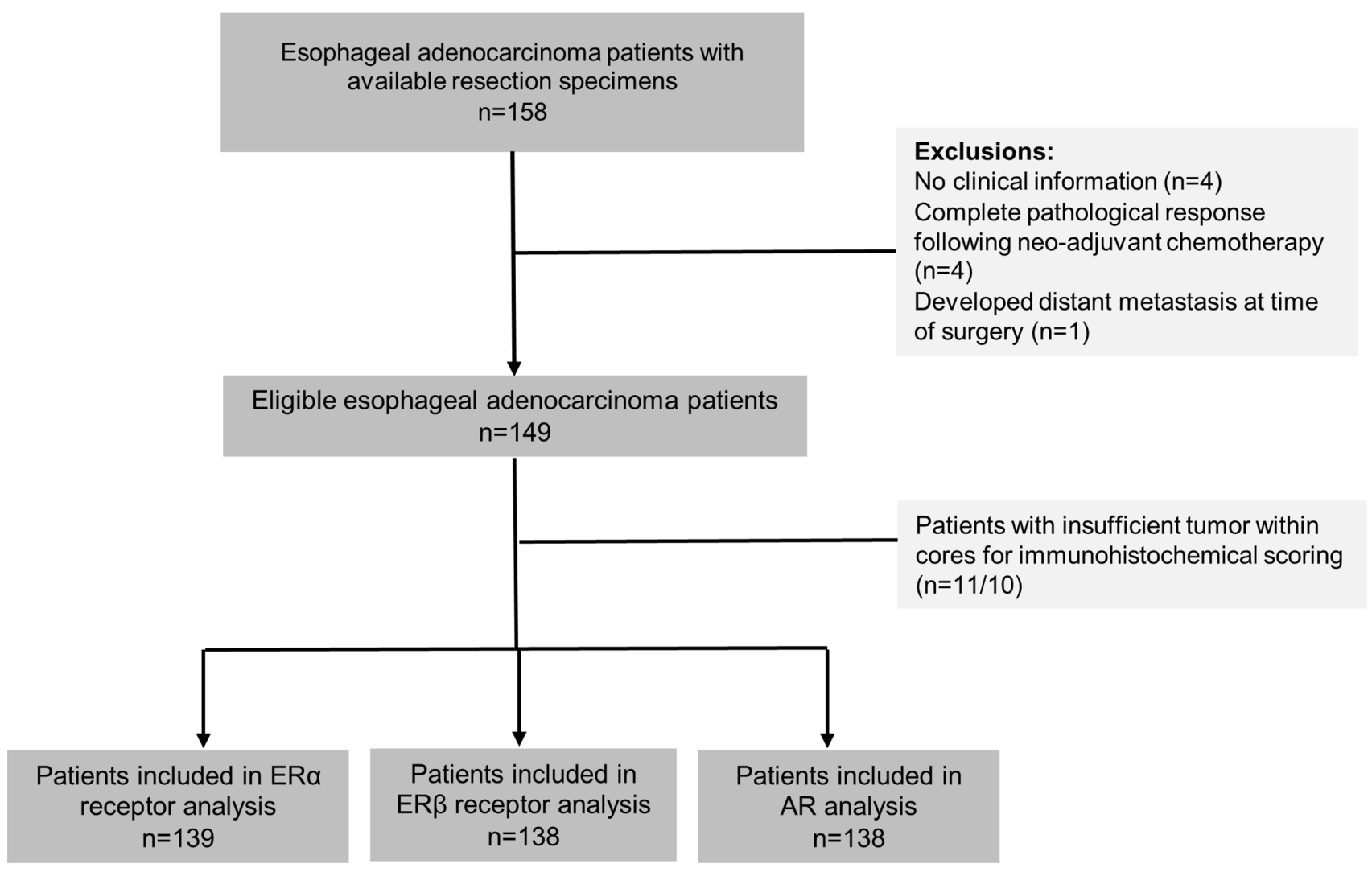

Figure 1: Study selection process for analysis of ER $\alpha, E R \beta$ and $A R$ expression in esophageal adenocarcinoma patients. Abbreviations: $\mathrm{ER}=$ estrogen receptor, $\mathrm{AR}=$ androgen receptor, $\alpha=$ alpha, $\beta=$ beta. 
Table 1: Characteristics of EAC patients by sex hormone receptor expression

\begin{tabular}{|c|c|c|c|c|c|c|c|c|c|}
\hline & \multicolumn{3}{|c|}{ ER $\alpha$ receptor status } & \multicolumn{3}{|c|}{ ERß receptor status } & \multicolumn{3}{|c|}{ AR status } \\
\hline & $\begin{array}{l}\text { Negative } \\
(n=133)\end{array}$ & $\begin{array}{c}\text { Positive } \\
(n=6)\end{array}$ & $P$ & $\begin{array}{c}\text { Negative } \\
(n=95)\end{array}$ & $\begin{array}{l}\text { Positive } \\
(n=43)\end{array}$ & $\boldsymbol{P}$ & $\begin{array}{l}\text { Negative } \\
(n=134)\end{array}$ & $\begin{array}{c}\text { Positive } \\
(n=4)\end{array}$ & $P$ \\
\hline \multicolumn{10}{|l|}{ Sex } \\
\hline Male & $104(78.2)$ & $5(83.3)$ & 0.76 & $74(77.9)$ & $34(79.1)$ & 0.88 & $104(77.6)$ & $4(100)$ & 0.28 \\
\hline Female & $29(21.8)$ & $1(16.7)$ & & $21(22.1)$ & $9(20.9)$ & & $30(22.4)$ & 0 & \\
\hline \multicolumn{10}{|c|}{ Age at diagnosis (years) } \\
\hline$<50$ & $13(9.8)$ & $1(16.7)$ & 0.71 & $10(10.5)$ & $4(9.3)$ & 0.94 & $14(10.4)$ & 0 & 0.60 \\
\hline $50-59$ & $24(18.0)$ & $2(33.3)$ & & $18(18.9)$ & $10(23.3)$ & & $26(19.4)$ & 0 & \\
\hline $60-70$ & $63(47.4)$ & $2(33.3)$ & & $45(47.4)$ & $19(44.2)$ & & $62(46.3)$ & $3(75)$ & \\
\hline$\geq 70$ & $33(24.8)$ & $1(16.7)$ & & $22(23.2)$ & $10(23.3)$ & & $32(23.9)$ & $1(25)$ & \\
\hline \multicolumn{10}{|l|}{ Smoking status } \\
\hline Non-smoker & $34(29.1)$ & $1(16.7)$ & 0.38 & $24(28.2)$ & $12(32.4)$ & 0.52 & $34(25.4)$ & $1(25)$ & 0.38 \\
\hline Ex-smoker & $29(24.8)$ & $3(50)$ & & $20(23.5)$ & $12(32.4)$ & & $32(23.9)$ & 0 & \\
\hline Current smoker & $54(46.1)$ & $2(33.3)$ & & $41(48.2)$ & $13(35.1)$ & & $52(38.8)$ & $3(75)$ & \\
\hline Unknown & 16 & 0 & & 10 & 6 & & 16 & 0 & \\
\hline \multicolumn{10}{|l|}{ Alcohol } \\
\hline Non-drinker & $42(37.5)$ & $2(33.3)$ & 0.84 & $28(34.6)$ & $16(44.4)$ & 0.58 & $42(37.2)$ & $1(25)$ & 0.62 \\
\hline Drinker & $70(62.5)$ & $4(66.7)$ & & $53(65.4)$ & $20(55.6)$ & & $71(62.8)$ & $3(75)$ & \\
\hline Unknown & 21 & 0 & & 14 & 7 & & 21 & 0 & \\
\hline \multicolumn{10}{|c|}{ Primary tumor site } \\
\hline Lower third & $22(16.5)$ & 0 & 0.28 & $15(15.8)$ & $7(16.3)$ & 0.94 & $22(16.4)$ & 0 & 0.38 \\
\hline $\begin{array}{l}\text { Gastro- } \\
\text { esophageal } \\
\text { junction }\end{array}$ & $111(83.5)$ & $6(100)$ & & $80(84.2)$ & $36(83.7)$ & & $112(83.6)$ & $4(100)$ & \\
\hline \multicolumn{10}{|c|}{ Siewert classification ${ }^{a}$} \\
\hline Siewert I & $65(58.6)$ & $4(66.7)$ & 0.69 & $48(60)$ & $21(58.3)$ & 0.87 & $66(58.9)$ & $2(50)$ & 0.72 \\
\hline Siewert II/III & $46(41.4)$ & $2(33.3)$ & & $32(40)$ & $15(41.7)$ & & $46(41.1)$ & $2(50)$ & \\
\hline \multicolumn{10}{|l|}{ PET response } \\
\hline No & $40(40.8)$ & $4(66.7)$ & 0.21 & $28(39.4)$ & $16(48.5)$ & 0.38 & $44(43.6)$ & 0 & 0.22 \\
\hline Yes & $58(59.2)$ & $2(33.3)$ & & $43(60.6)$ & $17(51.5)$ & & $57(56.4)$ & $2(100)$ & \\
\hline Unknown & 35 & 0 & & 24 & 10 & & 33 & 2 & \\
\hline \multicolumn{10}{|c|}{ Lymphatic vascular invasion } \\
\hline No & $40(30.3)$ & $3(50)$ & 0.31 & $29(30.8)$ & $13(30.2)$ & 0.94 & $42(31.6)$ & 0 & 0.39 \\
\hline Yes & $92(69.7)$ & $3(50)$ & & $65(69.2)$ & $30(69.8)$ & & $91(68.4)$ & $4(100)$ & \\
\hline Unknown & 1 & 0 & & 1 & 0 & & 1 & 0 & \\
\hline \multicolumn{10}{|l|}{ Grade } \\
\hline Well & $4(3)$ & 0 & 0.87 & $4(4.2)$ & 0 & 0.32 & $4(3)$ & 0 & 0.84 \\
\hline Moderate & $51(38.3)$ & $2(33.3)$ & & 37 (38.9) & $15(34.9)$ & & $50(37.3)$ & $2(50)$ & \\
\hline Poor & $78(58.7)$ & $4(66.7)$ & & $54(56.8)$ & $28(65.1)$ & & $80(59.7)$ & $2(50)$ & \\
\hline \multicolumn{10}{|c|}{ Circumferential resection margin status } \\
\hline Negative & $72(54.5)$ & $3(50)$ & 0.83 & $54(57.5)$ & $19(44.2)$ & 0.15 & $73(54.9)$ & $1(25)$ & 0.24 \\
\hline Positive & $60(45.5)$ & $3(50)$ & & $40(42.5)$ & $24(55.8)$ & & $60(45.1)$ & $3(75)$ & \\
\hline
\end{tabular}




\begin{tabular}{|c|c|c|c|c|c|c|c|c|c|}
\hline Unknown & 1 & 0 & & 1 & 0 & & 1 & 0 & \\
\hline \multicolumn{10}{|c|}{ Surgical T stage } \\
\hline 1 & $11(8.3)$ & $1(16.7)$ & 0.87 & $8(8.4)$ & $4(9.3)$ & 0.95 & $11(8.2)$ & $1(25)$ & 0.53 \\
\hline 2 & $26(19.6)$ & $1(16.7)$ & & $16(16.8)$ & $8(18.6)$ & & $26(19.4)$ & 0 & \\
\hline 3 & $91(68.4)$ & $4(66.7)$ & & $67(70.5)$ & $30(69.8)$ & & $92(68.7)$ & $3(75)$ & \\
\hline 4 & $5(3.8)$ & 0 & & $4(4.2)$ & $1(2.3)$ & & $5(3.7)$ & 0 & \\
\hline \multicolumn{10}{|c|}{ Surgical N stage } \\
\hline 0 & $45(33.8)$ & $2(33.3)$ & 0.04 & $31(32.6)$ & $15(34.8)$ & 0.23 & $45(33.6)$ & $1(25)$ & 0.51 \\
\hline 1 & $29(21.8)$ & 0 & & $23(24.2)$ & $6(14)$ & & $28(20.9)$ & $1(25)$ & \\
\hline 2 & $32(24.1)$ & 0 & & $23(24.2)$ & $8(18.6)$ & & $30(22.4)$ & $2(50)$ & \\
\hline & $27(20.3)$ & $4(66.7)$ & & $18(19)$ & $14(32.6)$ & & $31(23.1)$ & 0 & \\
\hline
\end{tabular}

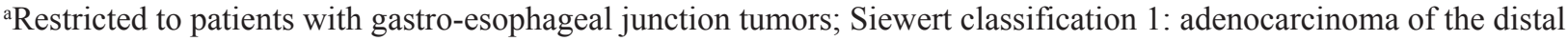
esophagus, 2: true carcinoma of the cardia arising at the esophago-gastric junction, 3: subcardial gastric cancer infiltrating distal esophagus. $\mathrm{ER}=$ estrogen receptor, $\alpha=$ alpha, $\beta=$ beta, $\mathrm{AR}=$ androgen receptor, $\mathrm{GEJ}=$ gastro-esophageal junction, $\mathrm{PET}=$ positron emission tomography, $\mathrm{T}=$ tumor, $\mathrm{N}=$ nodal.

survival. This is the first study to investigate sex hormone receptor expression in EAC patients by tumor location and there was a suggestion that ER $\beta$ expression was associated with a reduction in the risk of all-cause and cancer-specific death in patients with GEJ cancer, albeit findings did not reach statistical significance.

Previous research into sex hormone receptor expression in EAC has been sparse and contradictory

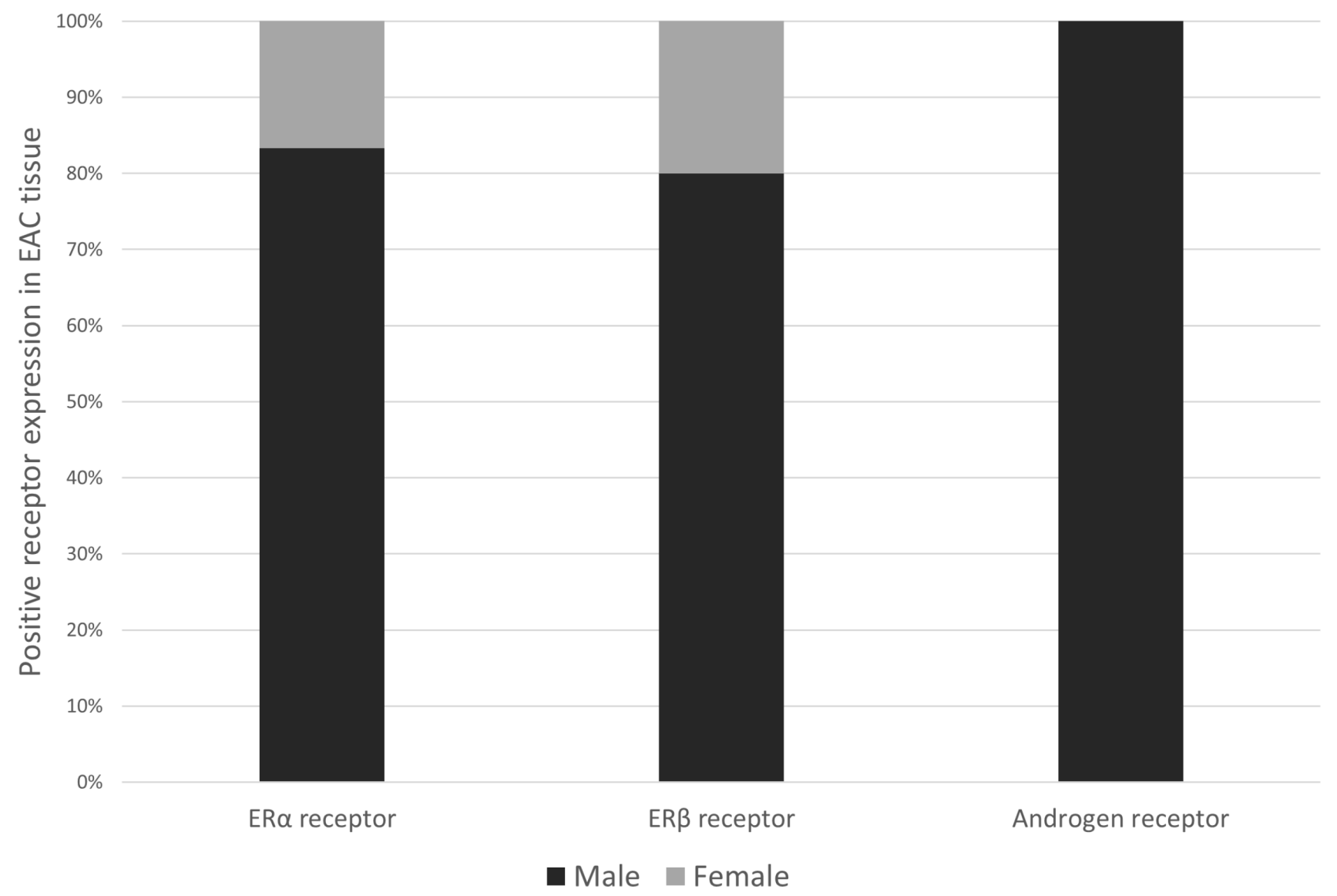

Figure 2: Bar chart showing sex distribution (\%) among esophageal adenocarcinoma patients who scored positively for $\operatorname{ER} \alpha(n=6), \operatorname{ER} \beta(n=43)$ or AR $(n=4)$ expression. Abbreviations: $\mathrm{ER}=$ estrogen receptor, $\mathrm{AR}=$ androgen receptor, $\alpha=$ alpha, $\beta=$ beta. 
A

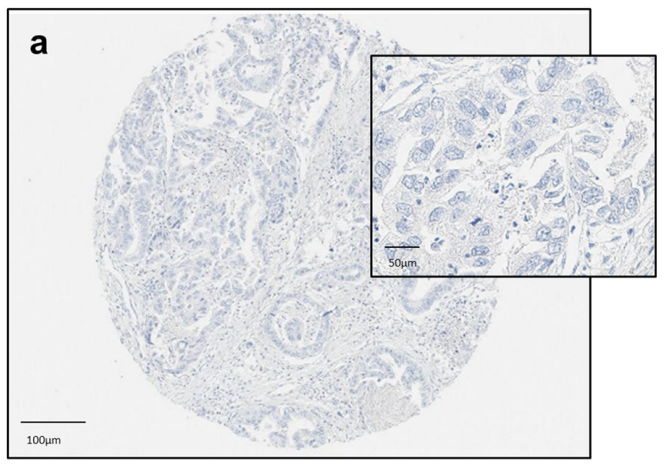

B
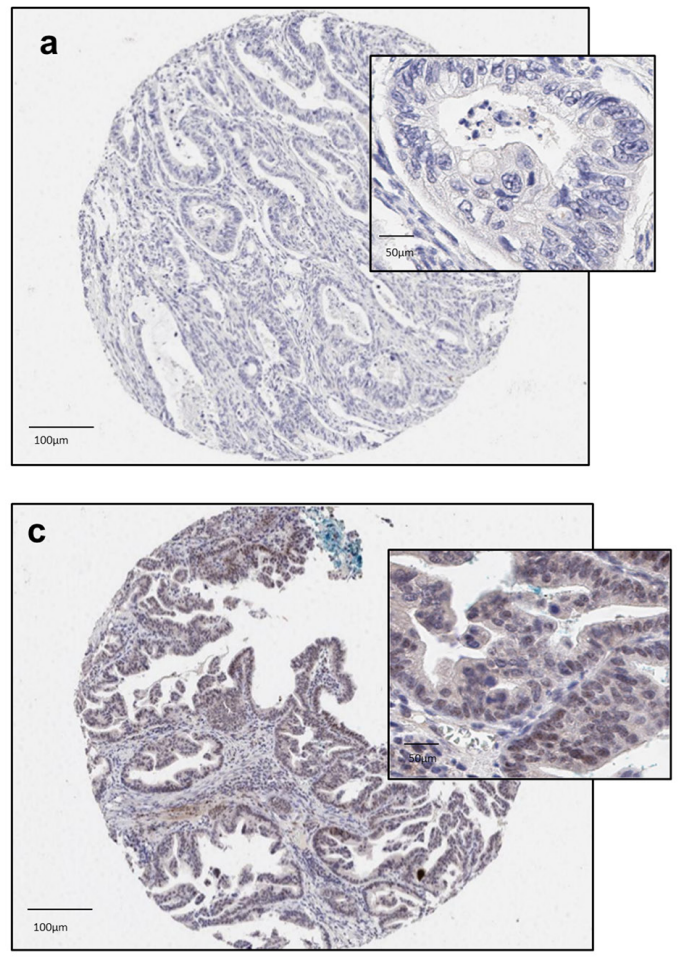

C

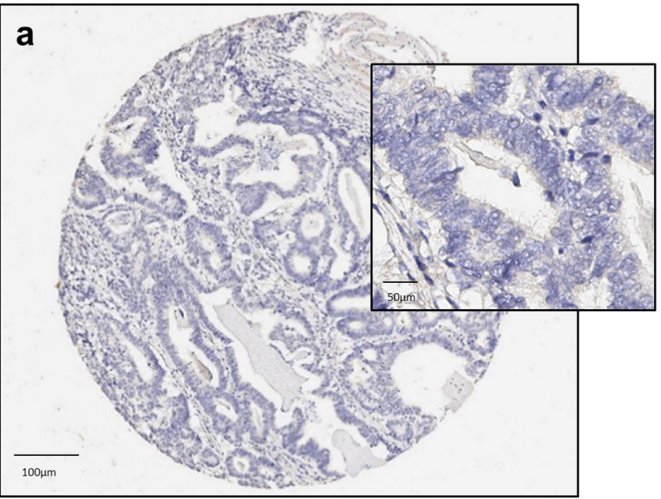

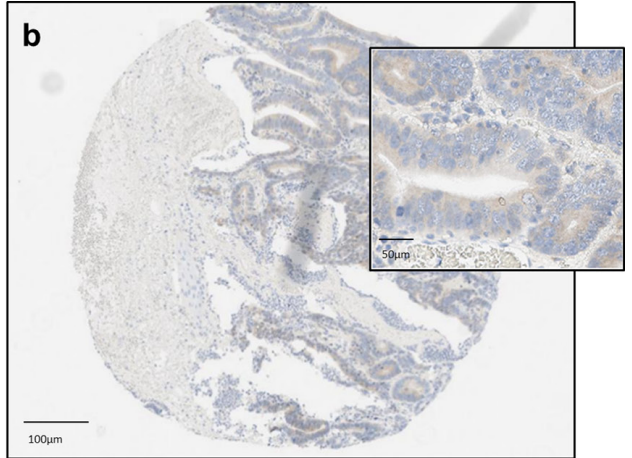
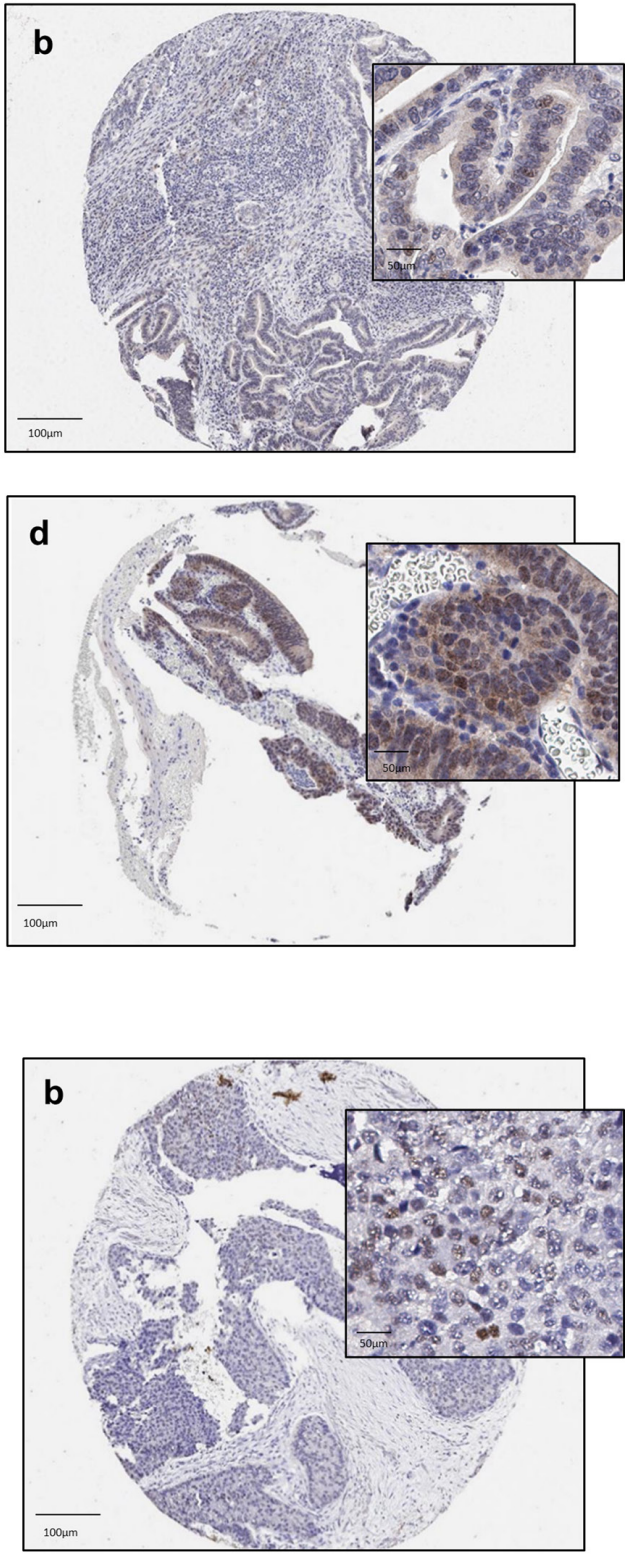

Figure 3: (A-C) Tissue microarray staining in esophageal adenocarcinoma core samples according to ER $\alpha(A), E R \beta$ (B) and AR expression. a: no staining [intensity 0]; b: weak staining [intensity 1]; c: moderate staining [intensity 2]; d: strong staining [intensity 3]. NB. No cores had ER-alpha and androgen receptor biomarkers scored at intensity $2 / 3$. Abbreviations: $E R=$ estrogen receptor, $\mathrm{AR}=$ androgen receptor, $\alpha=$ alpha, $\beta=$ beta. 
Table 2: Overall survival, cancer-specific survival and recurrence-free survival according to sex hormone receptor expression

\begin{tabular}{|c|c|c|c|c|c|c|c|c|c|c|c|c|}
\hline \multirow[b]{2}{*}{ Biomarker } & \multicolumn{4}{|c|}{ Overall survival } & \multicolumn{4}{|c|}{ Cancer-specific survival } & \multicolumn{4}{|c|}{ Recurrence-free survival } \\
\hline & Events & Patients & $\begin{array}{c}\text { Unadjusted } \\
\text { HR } \\
(95 \% \mathrm{CI})\end{array}$ & $\begin{array}{c}\text { Adjusted } \\
\text { HR }^{\mathrm{a}} \\
(95 \% \mathrm{CI})\end{array}$ & Events & Patients & $\begin{array}{c}\text { Unadjusted } \\
\text { HR } \\
(95 \% \mathrm{CI})\end{array}$ & $\begin{array}{l}\text { Adjusted } \\
\text { HR }^{\mathrm{a}} \\
(95 \% \mathrm{CI})\end{array}$ & Events & Patients & $\begin{array}{c}\text { Unadjusted } \\
\text { HR } \\
(95 \% \mathrm{CI})\end{array}$ & $\begin{array}{c}\text { Adjusted } \\
\text { HR }^{\mathrm{a}} \\
(95 \% \mathrm{CI})\end{array}$ \\
\hline \multicolumn{13}{|c|}{ Estrogen receptor $\alpha$} \\
\hline Negative & 79 & 133 & 1.00 & 1.00 & 75 & 129 & 1.00 & 1.00 & 82 & 129 & 1.00 & 1.00 \\
\hline Positive & 4 & 6 & $\begin{array}{c}1.45 \\
(0.53,3.98)\end{array}$ & $\begin{array}{c}1.32 \\
(0.41,4.24)\end{array}$ & 3 & 5 & $\begin{array}{c}1.21 \\
(0.38,3.87)\end{array}$ & $\begin{array}{c}1.14 \\
(0.29,4.50)\end{array}$ & 4 & 6 & $\begin{array}{c}1.29 \\
(0.17,2.79)\end{array}$ & $\begin{array}{c}1.36 \\
(0.44,4.23)\end{array}$ \\
\hline \multicolumn{13}{|c|}{ Estrogen receptor $\beta$} \\
\hline Negative & 56 & 95 & 1.00 & 1.00 & 52 & 91 & 1.00 & 1.00 & 56 & 91 & 1.00 & 1.00 \\
\hline Positive & 28 & 43 & $\begin{array}{c}1.14 \\
(0.72,1.80)\end{array}$ & $\begin{array}{c}0.71 \\
(0.41,1.21)\end{array}$ & 27 & 42 & $\begin{array}{c}1.14 \\
(0.72,1.82)\end{array}$ & $\begin{array}{c}0.73 \\
(0.42,1.28)\end{array}$ & 31 & 43 & $\begin{array}{c}1.28 \\
(0.82,2.00)\end{array}$ & $\begin{array}{c}0.89 \\
(0.53,1.48)\end{array}$ \\
\hline \multicolumn{13}{|c|}{ Androgen receptor } \\
\hline Negative & 79 & 134 & 1.00 & 1.00 & 74 & 129 & 1.00 & 1.00 & 82 & 130 & 1.00 & 1.00 \\
\hline Positive & 4 & 4 & $\begin{array}{c}2.29 \\
(0.83,6.33)\end{array}$ & $\begin{array}{c}1.50 \\
(0.49,4.62)\end{array}$ & 4 & 4 & $\begin{array}{c}2.42 \\
(0.88,6.72)\end{array}$ & $\begin{array}{c}1.48 \\
(0.48,4.55)\end{array}$ & 4 & 4 & $\begin{array}{c}1.98 \\
(0.72,5.43)\end{array}$ & $\begin{array}{c}1.50 \\
(0.49,4.57)\end{array}$ \\
\hline
\end{tabular}

Abbreviations: $\mathrm{HR}=$ Hazard ratio, $\mathrm{CI}=$ Confidence interval, $\alpha=$ alpha, $\beta=$ beta.

${ }^{a}$ Adjusted for age at diagnosis, sex, nodal status, grade, PET response, circumferential resection margin status, lymphatic vascular invasion, primary site, smoking.

Table 3: Sex hormone receptor expression and EAC progression restricting to patients with gastro-esophageal junction tumors

\begin{tabular}{|c|c|c|c|c|c|c|c|c|c|c|c|c|}
\hline \multirow[b]{2}{*}{ Biomarker } & \multicolumn{4}{|c|}{ Overall survival } & \multicolumn{4}{|c|}{ Cancer-specific survival } & \multicolumn{4}{|c|}{ Recurrence-free survival } \\
\hline & Events & Patients & $\begin{array}{c}\text { Unadjusted } \\
\text { HR } \\
(\mathbf{9 5 \%} \text { CI) }\end{array}$ & $\begin{array}{c}\text { Adjusted } \\
\text { HR }^{\mathrm{a}} \\
(95 \% \mathrm{CI})\end{array}$ & Events & Patients & $\begin{array}{c}\text { Unadjusted } \\
\text { HR } \\
(95 \% \mathrm{CI})\end{array}$ & $\begin{array}{c}\text { Adjusted } \\
\text { HR }^{\mathrm{a}} \\
(95 \% \mathrm{CI})\end{array}$ & Events & Patients & $\begin{array}{c}\text { Unadjusted } \\
\text { HR } \\
(95 \% \mathrm{CI})\end{array}$ & $\begin{array}{l}\text { Adjusted } \\
\text { HRa } \\
(95 \% \text { CI })\end{array}$ \\
\hline \multicolumn{13}{|c|}{ Estrogen receptor $\alpha$} \\
\hline Negative & 69 & 111 & 1.00 & 1.00 & 65 & 107 & 1.00 & 1.00 & 71 & 108 & 1.00 & 1.00 \\
\hline Positive & 4 & 6 & $\begin{array}{c}1.40 \\
(0.51,3.87)\end{array}$ & $\begin{array}{c}1.18 \\
(0.36,3.90)\end{array}$ & 3 & 5 & $\begin{array}{c}1.18 \\
(0.37,3.78)\end{array}$ & $\begin{array}{c}1.00 \\
(0.24,4.08)\end{array}$ & 4 & 6 & $\begin{array}{c}1.16 \\
(0.42,3.18)\end{array}$ & $\begin{array}{l}1.20 \\
(0.38,3.77)\end{array}$ \\
\hline \multicolumn{13}{|c|}{ Estrogen receptor $\beta$} \\
\hline Negative & 50 & 80 & 1.00 & 1.00 & 46 & 76 & 1.00 & 1.00 & 46 & 77 & 1.00 & 1.00 \\
\hline Positive & 24 & 36 & $\begin{array}{c}1.00 \\
(0.61,1.64)\end{array}$ & $\begin{array}{c}0.58 \\
(0.33,1.03)\end{array}$ & 23 & 35 & $\begin{array}{c}0.99 \\
(0.60,1.64)\end{array}$ & $\begin{array}{c}0.59 \\
(0.32,1.07)\end{array}$ & 23 & 36 & $\begin{array}{c}1.14 \\
(0.71,1.84)\end{array}$ & $\begin{array}{l}0.75 \\
(0.43,1.29)\end{array}$ \\
\hline \multicolumn{13}{|c|}{ Androgen receptor } \\
\hline Negative & 69 & 112 & 1.00 & 1.00 & 64 & 107 & 1.00 & 1.00 & 71 & 109 & 1.00 & 1.00 \\
\hline Positive & 4 & 4 & $\begin{array}{c}2.22 \\
(0.80,6.18)\end{array}$ & $\begin{array}{c}1.77 \\
(0.55,5.67)\end{array}$ & 4 & 4 & $\begin{array}{c}2.38 \\
(0.85,6.63)\end{array}$ & $\begin{array}{c}1.70 \\
(0.53,5.47)\end{array}$ & 4 & 4 & $\begin{array}{c}1.91 \\
(0.69,5.26)\end{array}$ & $\begin{array}{l}2.07 \\
(0.66,6.51)\end{array}$ \\
\hline
\end{tabular}

Abbreviations: $\mathrm{HR}=$ Hazard ratio, $\mathrm{CI}=$ Confidence interval, $\alpha=$ alpha, $\beta=$ beta.

${ }^{a}$ Adjusted for age at diagnosis, sex, nodal status, grade, PET response, circumferential resection margin status, lymphatic vascular invasion, smoking.

(see Table 4). Similar to our study, earlier studies have identified positive ER $\beta$ expression [24-26, 28] and none or limited ER $\alpha$ expression $[24,25]$ in EAC. Additionally, in a small study of 33 patients, Liu et al. [26] reported that ER $\beta$ subtype isoforms (ER $\beta 1$, ER $\beta 2$, ER $\beta 3$ and ER $\beta 5$ ) were overexpressed in EAC compared to precursor lesions. Similar to our study, Al-Kyatt et al. [24] found limited $\mathrm{ER} \alpha$ receptor expression ( $n=1$ case, defined as a H-score of 10), while moderate ER $\beta$ receptor expression was detected $(n=14$ cases $(40 \%)$, defined as a H-score of 30$)$ [24]. Although the authors did not separate findings by histological subtype, the majority of the cohort $(76 \%)$ had EAC. The authors also used quantitative reverse transcription polymerase chain reaction to evaluate ER tumor expression and reported that
ER $\beta$ expression (ESR1, based on mRNA levels) was correlated with a shorter 1-year diseasespecific survival $(p=0.05)$, suggesting that ER $\beta$ may be a marker of poor biological behavior in EAC [24]. However, most likely due to small numbers ( $n=28$ EAC patients), a formal survival analysis was not conducted therefore limiting comparison with our study.

In a small study of 31 EAC patients with available esophagectomy specimens, Akgun and colleagues [28] reported expression of ER $\beta$ in Barrett's metaplasia negative for dysplasia, low-grade dysplasia, high-grade dysplasia and adenocarcinoma and observed a trend of increased expression as esophageal lesions progressed. Similarly, other studies have noted higher expression of ER $\beta$ in EAC compared to Barrett's esophagus [26] and normal esophageal mucosa [25], and poorer differentiation 
Table 4: Previous studies of ER $\alpha, E R \beta$ and AR expression and survival in esophageal adenocarcinoma cohorts

\begin{tabular}{|c|c|c|c|c|c|c|c|c|c|}
\hline \multirow[b]{2}{*}{ Study (year) } & \multirow[b]{2}{*}{ Location } & \multirow{2}{*}{$\begin{array}{l}\text { Hormone } \\
\text { receptor }\end{array}$} & \multicolumn{2}{|c|}{ Number of patients } & \multirow{2}{*}{$\begin{array}{l}\text { Antibody } \\
\text { (dilution) }\end{array}$} & \multirow{2}{*}{$\begin{array}{c}\text { Positive expression } \\
\text { cut-off value } \\
\text { (range) }\end{array}$} & \multirow[b]{2}{*}{ Mortality } & \multirow{2}{*}{$\begin{array}{c}\text { HR } \\
(95 \% \text { CI })\end{array}$} & \multirow[b]{2}{*}{$p$} \\
\hline & & & $\begin{array}{c}\text { Positive } \\
\text { expression }\end{array}$ & $\begin{array}{l}\text { Negative } \\
\text { expression }\end{array}$ & & & & & \\
\hline \multirow[t]{2}{*}{$\begin{array}{l}\text { Al-Kyatt } \\
(2018)^{\mathrm{a}}\end{array}$} & UK & $\mathrm{ER} \alpha$ & 1 & 33 & Mouse (1:40) & $\mathrm{H}$-score $\geq 10$ & $\mathrm{CS}$ & NR & $0.05^{\mathrm{b}}$ \\
\hline & & $\mathrm{ER} \beta$ & 14 & 20 & & & $\mathrm{CS}$ & NR & $0.02^{\mathrm{b}}$ \\
\hline \multirow[t]{2}{*}{$\begin{array}{l}\text { Kalayarasan } \\
(2008)^{c}\end{array}$} & India & $\mathrm{ER} \alpha$ & 0 & 15 & $\begin{array}{c}\text { Mouse } \\
\text { (Prediluted) }\end{array}$ & Quick score $\geq 1(0-7)^{\mathrm{d}}$ & NR & NR & NR \\
\hline & & $\mathrm{ER} \beta$ & 15 & 0 & Mouse (1:50) & & & & \\
\hline \multirow[t]{4}{*}{ Liu (2004) } & USA & $\mathrm{ER} \beta-1$ & 23 & 4 & NR & $\geq 1 \% \mathrm{e}^{\mathrm{e}}$ & NR & NR & NR \\
\hline & & $\mathrm{ER} \beta-2$ & 22 & 5 & & & & & \\
\hline & & $E R \beta-3$ & 27 & 0 & & & & & \\
\hline & & $\mathrm{ER} \beta-5$ & 27 & 0 & & & & & \\
\hline Akgun (2002) & USA & $\mathrm{ER} \beta$ & 23 & 0 & Rabbit (1:500) & $\geq 1 \%$ staining in cells & NR & NR & NR \\
\hline Awan (2007) & UK & $\mathrm{AR}$ & 13 & 5 & Mouse (1:50) & $\begin{array}{l}\text { Any focal/diffuse } \\
\text { staining }^{f}\end{array}$ & $\mathrm{AC}$ & NR & NS \\
\hline \multirow[t]{2}{*}{ Tiffin (2003) } & UK & ER & 8 & 12 & NR & $\begin{array}{l}\text { Any mild, moderate or } \\
\text { heavy staining }\end{array}$ & NR & NR & NR \\
\hline & & AR & 1 & 19 & & & & & \\
\hline Tihan (2001) & USA & $\mathrm{AR}$ & 5 & 6 & Mouse (1:200) & $\begin{array}{l}\text { Any focal/diffuse } \\
\text { staining }^{\mathrm{h}}\end{array}$ & $\mathrm{AC}$ & NR & NS \\
\hline
\end{tabular}

Abbreviations: $\mathrm{ER}=$ estrogen receptor, $\mathrm{AR}=$ androgen receptor, $\mathrm{NR}=$ Not reported; $\mathrm{NS}=$ Non-significant; $\mathrm{AC}=\mathrm{All}$-cause; $\mathrm{CS}=\mathrm{Cancer}$-specific, $\alpha=$ alpha; $\beta=$ beta

ancludes esophageal adenocarcinoma $(n=28)$ and esophageal squamous cell carcinoma (6) patients.

${ }^{b}$ Survival correlated with ER $\alpha$ (ESR1) and ER $\beta$ (ESR2) expression quantified using quantitative reverse transcription polymerase chain reaction.

${ }^{\mathrm{C} E n d o s c o p i c ~ b i o p s y ~ s p e c i m e n s ~ u s e d ~ t o ~ d e t e r m i n e ~ s e x ~ h o r m o n e ~ r e c e p t o r ~ e x p r e s s i o n . ~}$

${ }^{d}$ Receptor expression reported as ' $0=$ no staining'; ' 1 = weak intensity (only visible at high magnification)'; ' $2=$ moderate intensity (readily visible at low magnification)'; ' $3=$ strong (strikingly positive even at low power. magnification)'; added to score for $\%$ of cells stained $(0=0 \% ; 1=1-25 \% ; 2=26-50 \%$; $3=51-75 \% ; 4=76-100 \%)$. Mean quick score was 6.6 for ER $\beta$.

${ }^{\text {e}}$ Receptor expression reported as $\%$ of cells stained $(0=0 \% ; 1=1 \%$ to $10 \% ; 2=11 \%$ to $25 \% ; 3=26 \%$ to $50 \% ; 4=51 \%$ to $75 \% ; 5 \geq 75 \%$ ).

'Receptor expression reported as 'no staining'; 'focal positivity' or 'diffuse positivity'.

'Receptor expression reported as 'absent'; 'mild staining'; 'moderate staining' or 'heavy staining'.

heceptor expression reported as 'no staining'; 'focal positivity' or 'diffuse positivity'.

in EAC tumors that express $\operatorname{ER} \beta[25,28]$. We did not find any significant differences in tumor grade according to sex hormone receptor expression. Some [30, 29] but not all previous studies [27] have reported weak-to moderate positive expression for AR in EAC with no differences in survival noted by expression status [30,29] but sample sizes have been small (e.g. less than 20 EAC patients). In a small study of 11 EAC patients, Tihan et al. [30] noted that patients with AR-negative tumors included a larger proportion of longer-term survivors compared to patients with AR-positive tumors but no statistically significant difference in survival was apparent and no formal survival analysis was conducted. Variation in terms of sample sizes, selected patient groups, methods used to quantify receptor expression, as well as a lack of adjustment for important confounders in previous studies make direct comparisons with our study difficult.

In our study, positive expression of ER $\beta$ was predominantly limited to males, which could be suggestive of a potential biological role for estrogen and/or ER $\beta$ receptor in EAC development. Within the minority of patients whose tumors expressed ER $\alpha$ and $\mathrm{AR}$, the majority of expression was also detected in male EAC patients. Preclinical data have shown that estrogen and selective estrogen receptor modulator treatment decreases tumor growth, proliferation and increase apoptosis in EAC and Barrett's esophagus cell lines [13, 14] and similar effects have been reported in vitro and in vivo for gastric [31, 32] and colorectal cancer [33] and esophageal squamous cell carcinoma (OSSC) [20, 34]. Interestingly, ER $\beta$ has been correlated with improved survival in non-small cell lung adenocarcinoma, particularly in men [35], although findings from other studies have been mixed $[36,37]$ and a recent pooled analyses found no association between ER $\beta$ expression and survival in NSCLC patients [38].

A possible mechanism of estrogen 'protection' might be mediated through estrogen receptors however, the role of activation of these receptors in re-epithelialisation following injury, and in the development of precursor states and EAC remains unclear. AR has been shown to be an important mediator of inflammatory signals in esophageal cancer progression [20] and overexpression of AR in vivo has been shown to promote cell migration, invasion and proliferation in esophageal cancer $[13,20]$. Although risk estimates for EAC survival in our study 
suggested potential inverse associations for ER $\beta$ and positive associations for AR expression, our results were not statistically significant. Expression of sex hormone receptors, in particular ER $\beta$, in EAC and their relationship with EAC development and progression therefore merits further investigation in larger population-based cohorts. Moreover, studies should include sufficient numbers of females to enable more meaningful sex-specific comparisons.

In our study, sensitivity analysis suggested that ER $\beta$ expression was associated with more marked reductions in all-cause and cancer-specific mortality in patients diagnosed with GEJ cancer. Although not as marked as EAC, gastric cardia adenocarcinomas, located close to the GEJ, show a similar sex disparity in incidence compared to EAC $[10,11]$ and proximal gastric cancers share similar aetiology and patterns of incidence with EAC [39]. Increased $E R \beta$ expression has been demonstrated in gastric cancer tissue compared to normal tissue [40,41] and its presence has been associated with poorer prognosis $[42,43]$ however, other studies have shown no such association [40,44]. No study has specifically investigated ER $\beta$ expression in cancer tissues of the proximal stomach. Epidemiological studies of markers of endogenous and exogenous estrogen exposures have suggested protective associations for gastric cancer [45], which are possibly more marked for gastric cardia adenocarcinomas [46], and preclinical evidence shows an increase in apoptosis and an inhibition of cell migration with estrogen administration in gastric cancer cell lines [32, 47]. A more marked prognostic benefit for ER receptor expression in GEJ tumors is therefore plausible but findings require replication in other large EAC cohorts. We did not have information on sex hormone receptor isoforms, which limited our ability to identify overexpression events directly linked to clinical EAC outcomes. Future studies should aim to investigate the complex interplay between wild-type and variant forms of sex hormone receptor expression in EAC and their relationship with prognosis. Moreover, considering the potential for interand intra-nuclear receptor crosstalk within ER, studies that examine alternative gene splicing via transcriptomic analysis of EAC tumour specimens both before and after chemotherapy may be warranted. Despite being the largest study conducted to examine the association between ER $\beta$ expression and EAC progression, caution is required in the interpretation of these results for GEJ patients as analysis was secondary in nature and based on reduced number of patients.

Our study had a number of strengths and limitations. This is the first population-representative study to investigate sex hormone receptor expression in EAC tissue and their association with prognostic outcomes. Although we restricted our cohort to patients who underwent neoadjuvant chemotherapy prior to surgical resection, neoadjuvant therapy is now an integral component of EAC management [48] and we included all patients who underwent these treatments in Northern Ireland during the study period. Although progesterone receptor expression has been shown to be absent in both normal epithelial mucosa and oesophageal tumours [24], we did not investigate its expression, or expression of membrane bound G-protein coupled receptors (e.g. G protein-coupled estrogen receptor 1; GPER or GPR30). Future studies should explore the role of these additional receptors in OAC progression. Our study benefitted from a long follow-up period of (up to 9 years) and we had detailed clinico-pathological information, which allowed adjustment for confounders. Two observers (including a trained pathologist) independently scored all tumor cores and were blinded to clinical data. We utilised EAC tissue treated with chemotherapy, however it is unclear how treatment influences expression of sex hormone receptors. We used triplicate tumor cores to generate $\mathrm{H}$-scores, thus limiting the potential for sampling bias. Insufficient tissue in diagnostic biopsies prohibited investigation of sex hormone receptor expression in EAC tissue prior to chemotherapy administration; however, pretreatment endoscopic biopsies may be subject to sampling error. Finally, although our study is the largest to date to examine sex hormone receptor expression and EAC outcomes, expression of $E R \alpha$ and $A R$ was observed in only a minority of patients and small case numbers limited sensitivity and sub-group analyses (e.g. by sex).

\section{MATERIALS AND METHODS}

\section{Study cohort}

We included all EAC patients who underwent neoadjuvant chemotherapy prior to surgical resection in Northern Ireland between 2004 and 2012. All patients received cisplatin-based neo-adjuvant chemotherapy at the Northern Ireland Cancer Centre followed by surgical resection at one of four regional surgical centres. EAC resection specimens were accessed through the Northern Ireland Biobank (NIB) (study number NIB150176) which has ethical approval for the collection and storage of tumor tissue to support translational research [49]. To be included, patients had to have non-metastatic disease, have at least one available TMA tissue core with sufficient tumor for immunohistochemical scoring and have available clinico-pathological data. This study is in accordance with the Reporting Recommendations for Tumor Marker Prognostic Studies (REMARK) guidelines [50].

\section{Clinico-pathological variables and follow-up}

Clinical data were retrieved from a medical note review within the Northern Ireland Cancer Centre and pathology reports were reviewed for information on TNM 
stage, tumor grade, primary tumor site, positron emission tomography (PET) response, lymphovascular invasion and circumferential margin involvement. EAC tumors were classified according to location using the Siewert classification [51]. Pathological staging was defined according to International Union Against Cancer (UICC) TNM staging, 7th edition. Information on study outcomes were retrieved from the Northern Ireland Cancer Centre and included overall survival (time to death from any cause), cancer-specific survival (time to death from EAC) and recurrence-free survival (time to clinical or pathological recurrence or death). Patients were followed from the date of EAC diagnosis until recurrence, death or end of study follow-up (31st December 2014).

\section{Tumor molecular analysis}

\section{Tissue microarray construction and immunohistochemistry}

Tissue microarrays (TMAs) were created within the Northern Ireland Molecular Pathology Laboratory (NI-MPL) at Queen's University Belfast. A detailed description of TMA construction methods within the Northern Ireland Biobank are described elsewhere [52]. Immunohistochemical analysis was also conducted within the NI-MPL, where all markers were validated to investigate their association with other tumor sites (e.g. breast, prostate). A 3- $\mu \mathrm{m}$ thick section was deparafinized and endogenous peroxidase activity quenched with $0.3 \%$ hydrogen peroxide prior to slide labelling and staining using the Ventana Discovery $X^{\circledR}$ automated immunostainer (Ventana Medical Systems Inc, Tuscon, AZ) or the Bond Automated IHC/ISH Stainer (Leica Biosystems, Milton Keynes, UK). Slides were stained with rabbit (ER $\alpha$ ) or mouse (AR, ER $\beta$ ) monoclonal antibodies specific to the relevant sex hormone receptor. Antibody commercial suppliers included Ventana (cat no. 790-4324) for ER $\alpha$, Dako (cat no. M7292) for ER $\beta$ and Abcam (cat no. ab9474) for AR. Cell signalling-clone numbers (and dilutions) were as follows; ER $\alpha$ : SP1 (RTU dilution), ER $\beta$ : PPG5/10 (dilution 1 in 100) and AR: AR441 (1 in 200 dilution).

\section{Biomarker scoring and assessment}

Individual biomarker expression was assessed by two independent observers (JT \& ÚMcM) using an online image viewer PathXL, following training and guidance from an expert gastrointestinal pathologist (DMcM). Both observers were blinded to clinical data. Nuclear, cytoplasmic or cell membrane staining was considered and we quantified sex hormone receptor expression by calculating $\mathrm{H}$-scores that incorporated staining intensity and frequency, with consensus agreement of discordant results. Scoring was based on intensity $(0=$ no staining, $1=$ weak, 2 = moderate and $3=$ strong staining observed) and percentage of tumor cells staining positive. These two values were multiplied to give a $\mathrm{H}$-score between 1 and 300 and the maximum H-score from the three cores was used for analysis. A dichotomous classification was used to categorise maximum H-scores into positive (any) or negative expression.

\section{Statistical analysis}

Differences between clinico-pathological characteristics according to ER $\alpha, E R \beta$ and AR expression were calculated using chi-squared tests. Associations between sex hormone receptor expression (positive versus negative) and recurrence-free, cancer-specific and overall survival were investigated using Cox proportional hazards regression producing unadjusted and adjusted hazard ratios (HR) and 95\% confidence intervals (CIs). All analyses were adjusted for age at diagnosis, sex, pathological nodal stage, grade, primary site (lower third or gastro-esophageal junction (GEJ)), lymphovascular invasion, circumferential margin involvement, PET response and smoking. An unknown category was included for missing values for smoking and PET response. Sensitivity analysis was conducted restricting the cohort to patients diagnosed with cancers of the GEJ. Due to the small number of females included, we were unable to conduct sub-group analysis by sex. All statistical analysis was performed using STATA 14 (StataCorp LP, College Station, TX, USA).

\section{CONCLUSIONS}

In a population-based cohort of EAC patients who underwent neo-adjuvant chemotherapy prior to surgical resection, we found little evidence of $\mathrm{ER} \alpha$ or AR expression in EAC. Expression of ER $\beta$ was identified in one third of tumors, and although no significant associations were observed for the whole cohort, there was suggestive evidence that ER $\beta$ expression was associated with improved survival in patients with GEJ cancer. Considering that surgery alone is not a curative option for all stages of EAC and further therapeutic modalities are urgently required, further investigation is warranted to determine if the ER system could be a potential prognostic biomarker in EAC.

\section{Abbreviations}

EAC: esophageal adenocarcinoma; ER: estrogen receptor; AR: androgen receptor; FFPE: formalin-fixed paraffin embedded; GEJ: gastro-esophageal junctional; yp: pathologic stage classification determined after preoperative therapy. 


\section{Author contributions}

Study conception and design: Richard C. Turkington; Helen G. Coleman, Stephen McQuaid, Jacqueline A. James and Manuel Salto-Tellez; Data acquisition: Richard C. Turkington; Úna C. Mc Menamin, Helen G. Coleman, Stephen McQuaid and Jacqueline A. James and Damian T McManus; Data analysis and interpretation: Úna C. Mc Menamin, James Trainor, Helen G. Coleman, Richard C. Turkington and Damian T McManus; Drafting manuscript: Úna C. Mc Menamin, Helen G. Coleman, Richard C. Turkington; Manuscript revision: All. Final approval: All.

\section{ACKNOWLEDGMENTS}

Belfast Health and Social Care Trust; Cancer Research UK; HSC Research and Development Division of the Public Health Agency in Northern Ireland.

\section{CONFLICTS OF INTEREST}

The authors declare no conflicts of interest.

\section{FUNDING}

This work was supported by funding from the Northern Ireland Cancer Translational Research Group and the Gastrointestinal Cancer Research Charitable Fund administered by the Belfast Health and Social Care Trust and the Cancer Research UK Experimental Cancer Medicine Centre Initiative. Tissue samples used in this research were received from the Northern Ireland Biobank (NIB) which is funded by HSC Research and Development Division of the Public Health Agency in Northern Ireland and Cancer Research UK through the Belfast Cancer Research UK Centre and the Northern Ireland Experimental Cancer Medicine Centre; additional support was received from the Friends of the Cancer Centre. The Northern Ireland Molecular Pathology Laboratory has received funding from Cancer Research UK, the Friends of the Cancer Centre and the Sean Crummey Foundation. ÚMcM is funded by a Cancer Research UK Population Research Postdoctoral Fellowship and HGC is a co-investigator of the UKCRC Centre of Excellence for Public Health Northern Ireland. The study funders played no role in the study design or collection, analysis, and interpretation of data.

\section{REFERENCES}

1. Coleman HG, Xie SH, Lagergren J. The Epidemiology of Esophageal Adenocarcinoma. Gastroenterology. 2018; 154:390-405.

2. Castro C, Bosetti C, Malvezzi M, Bertuccio P, Levi F, Negri E, La Vecchia C, Lunet N. Patterns and trends in esophageal cancermortality and incidence in Europe (1980-2011) and predictions to 2015. Ann Oncol. 2014; 25:283-90.

3. Cunningham D, Allum WH, Stenning SP, Thompson JN, Van de Velde CJ, Nicolson M, Scarffe JH, Lofts FJ, Falk SJ, Iveson TJ, Smith DB, Langley RE, Verma M, et al. MAGIC Trial Participants. Perioperative Chemotherapy versus Surgery Alone for Resectable Gastresophageal Cancer. N Engl J Med. 2008; 372:1589-1597.

4. Allum WH, Stenning SP, Bancewicz J, Clark PI, Langley RE. Long-term results of a randomized trial of surgery with or without preoperative chemotherapy in esophageal cancer. J Clin Oncol. 2009; 27:5062-5067.

5. Bhat SK, McManus DT, Coleman HG, Johnston BT, Cardwell CR, McMenamin U, Bannon F, Hicks B, Kennedy G, Gavin AT, Murray LJ. Oesophageal adenocarcinoma and prior diagnosis of Barrett's oesophagus: a population-based study. Gut. 2015; 64:20-25.

6. de Jonge PJ, van Blankenstein M, Grady WM, Kuipers EJ. Barrett's esophagus: Epidemiology, cancer risk and implications for management. Gut. 2014; 63:191-202.

7. Lagergren J, Lagergren P. Recent developments in esophageal adenocarcinoma. CA Cancer J Clin. 2013; 63:232-48.

8. Freedman ND, Derakhshan MH, Abnet CC, Schatzkin A, Hollenbeck AR, McColl KE. Male predominance of upper gastrointestinal adenocarcinoma cannot be explained by differences in tobacco smoking in men versus women. Eur J Cancer. 2010; 46:2473-8.

9. Chandanos E, Lagergren J. Estrogen and the enigmatic male predominance of gastric cancer. Eur J Cancer. 2008; 44:2397-403.

10. Coupland VH, Allum W, Blazeby JM, Mendall MA, Hardwick RH, Linklater KM, Møller H, Davies EA. Incidence and survival of esophageal and gastric cancer in England between 1998 and 2007, a population-based study. BMC Cancer. 2012; 12:11.

11. Cook MB, Dawsey SM, Freedman ND, Inskip PD, Wichner SM, Quraishi SM, Devesa SS, McGlynn KA. Sex disparities in cancer incidence by period and age. Cancer Epidemiol Biomarkers Prev. 2009; 18:1174-82.

12. Yang H, Sukocheva OA, Hussey DJ, Watson DI. Estrogen, male dominance and esophageal adenocarcinoma: Is there a link. World J Gastroenterol. 2012; 18:393-400.

13. Sukocheva OA, Li B, Due SL, Hussey DJ, Watson DI. Androgens and esophageal cancer: what do we know? World J Gastroenterol. 2015; 21:6 146-56.

14. Petrick JL, Falk RT, Hyland PL, Caron P, Pfeiffer RM, Wood SN, Dawsey SM, Abnet CC, Taylor PR, Guillemette C, Murray LJ, Anderson LA, Cook MB. Association between circulating levels of sex steroid hormones and esophageal adenocarcinoma in the FINBAR Study. PLoS One. 2018; 13:e0190325.

15. Sugimachi K, Matsuoka H, Matsufuji H, Maekawa S, Kai $\mathrm{H}$, Okudaira Y. Survival rates of women with carcinoma of the esophagus exceed those of men. Surg Gynecol Obstet. 1987; 164:541-4. 
16. Morita M, Otsu H, Kawano H, Kasagi Y, Kimura Y, Saeki H, Ando K, Ida S, Oki E, Tokunaga E, Ikeda T, Kusumoto T, Maehara Y. Gender differences in prognosis after esophagectomy for esophageal cancer. Surg Today. 2014; 44:505-512.

17. Sukocheva OA, Wee C, Ansar A, Hussey DJ, Watson DI. Effect of estrogen on growth and apoptosis in esophageal adenocarcinoma cells. Dis Esophagus. 2013; 26:628-35.

18. Masaka T, Iijima K, Endo H, Asanuma K, Ara N, Ishiyama F, Asano N, Koike T, Imatani A, Shimosegawa T. Gender differences in esophageal mucosal injury in a reflux esophagitis model of rats. Gut. 2013; 62:6-14.

19. Utsumi Y, Nakamura T, Nagasue N, Kubota H, Morikawa $\mathrm{S}$. Role of estrogen receptors in the growth of human esophageal carcinoma. Cancer. 1989; 64:88-93.

20. Dong H, Xu J, Li W, Gan J, Lin W, Ke J, Jiang J, Du L, Chen Y, Zhong X, Zhang D, Yeung SJ, Li X, et al. Reciprocal androgen receptor/interleukin- 6 crosstalk drives esophageal carcinoma progression and contributes to patient prognosis. J Pathol. 2017; 241:448-462.

21. Rashid F, Khan RN, Iftikhar SY. Probing the link between estrogen receptors and esophageal cancer. World J Surg Oncol. 2010; 8:9.

22. Böttner M, Thelen P, Jarry H. Estrogen receptor beta: Tissue distribution and the still largely enigmatic physiological function. J Steroid Biochem Mol Biol. 2014; 139:245-251.

23. Filardo EJ, Thomas P. Minireview: G protein-coupled estrogen receptor-1, GPER: its mechanism of action and role in female reproductive cancer, renal and vascular physiology. Endocrinology. 2012; 153:2953-62.

24. Al-Khyatt W, Tufarelli C, Khan R, Iftikhar SF. Selective estrogen receptor antagonists inhibit esophageal cancer cell proliferation in vitro. BMC Cancer. 2018; 18:121.

25. Kalayarasan R, Ananthakrishnan N, Kate V, Basu D. Estrogen and progesterone receptors in esophageal carcinoma. Dis Esophagus. 2008; 21:298-303.

26. Liu L, Chirala M, Younes M. Expression of estrogen receptor-beta isoforms in Barrett's metaplasia, dysplasia and esophageal adenocarcinoma. Anticancer Res. 2004; 24:2919-24.

27. Tiffin N, Suvarna SK, Trudgill NJ, Riley SA. Sex hormone receptor immunohistochemistry staining in Barrett's esophagus and adenocarcinoma. Histopathology. 2003; 42:95-6.

28. Akgun H, Lechago J, Younes M. Estrogen receptorbeta is expressed in Barrett's metaplasia and associated adenocarcinoma of the esophagus. Anticancer Res. 2002; 22:1459-61.

29. Awan AK, Iftikhar SY, Morris TM, Clarke PA, Grabowska AM, Waraich N, Watson SA. Androgen receptors may act in a paracrine manner to regulate esophageal adenocarcinoma growth. Eur J Surg Oncol. 2007; 33:561-8.

30. Tihan T, Harmon JW, Wan X, Younes Z, Nass P, Duncan KL, Duncan MD. Evidence of androgen receptor expression in squamous and adenocarcinoma of the esophagus. Anticancer Res. 2001; 21:3107-14.

31. Tokunaga A, Onda M, Kiyama T, Nishi K, Mizutani T, Yoshiyuki T, Shimizu Y, Matsukura N, Tanaka N, Asano G. Contrasting actions of estradiol on the growth of human gastric cancer xenografts in nude mice. Jpn J Cancer Res. 1989; 80:1153-1155.

32. Pricci M, Linsalata M, Russo F, Messa C, Amati L, Caradonna L, Jirillo E, Di Leo A. Effects of 17beta-estradiol administration on apoptosis and polyamine content in AGS cell line. Anticancer Res. 2001; 21:3215-20.

33. Izbicki JR, Schmitz R, Hoppen HO, Izbicki W, Troidl H. Effects of steroid hormone therapy on primarily xenotransplanted human colorectal adenocarcinomas. J Cancer Res Clin Oncol. 1984; 108:345-350.

34. Ueo H, Matsuoka H, Sugimachi K, Kuwano H, Mori M, Akiyoshi T. Inhibitory effects of estrogen on the growth of a human esophageal carcinoma cell line. Cancer Res. 1990; 50:7212-7215.

35. Skov BG, Fischer BM, Pappot H. Oestrogen receptor beta over expression in males with non-small cell lung cancer is associated with better survival. Lung Cancer. 2008; 59:88-94.

36. Luo Z, Wu R, Jiang Y, Qiu Z, Chen W, Li W. Overexpression of estrogen receptor beta is a prognostic marker in non-small cell lung cancer: a meta-analysis. Int J Clin Exp Med. 2015; 8:8686-97.

37. Monica V, Longo M, Felice B, Scagliotti GV, Papotti M, Novello S. Role of hormone receptor expression in patients with advanced-stage lung cancer treated with chemotherapy. Clin Lung Cancer. 2012; 13:416-23.

38. Ma L, Zhan P, Liu Y, Zhou Z, Zhu Q, Miu Y, Wang X, Jin J, Li Q, Lv T, Song Y. Prognostic value of the expression of estrogen receptor $\beta$ in patients with non-small cell lung cancer: a meta-analysis. Transl Lung Cancer Res. 2016; 5:202-07.

39. Karimi P, Islami F, Anandasabapathy S, Freedman ND, Kamangar F. Gastric Cancer: Descriptive Epidemiology, Risk Factors, Screening, and Prevention. Cancer Epidemiol Biomarkers Prev. 2014; 23:700-713.

40. Gan L, He J, Zhang X, Zhang YJ, Yu GZ, Chen Y, Pan J, Wang JJ, Wang X. Expression profile and prognostic role of sex hormone receptors in gastric cancer. BMC Cancer. 2012; $12: 566$.

41. Wang M, Pan JY, Song GR, Chen HB, An LJ, Qu SX. Altered expression of estrogen receptor alpha and beta in advanced gastric adenocarcinoma: correlation with prothymosin alpha and clinicopathological parameters. Eur J Surg Oncol. 2007; 33:195-201.

42. Xu CY, Guo JL, Jiang ZN, Xie SD, Shen JG, Shen JY, Wang LB. Prognostic role of estrogen receptor alpha and estrogen receptor beta in gastric cancer. Ann Surg Oncol. 2010; 17:2503-9. 
43. Matsui M, Kojima O, Kawakami S, Uehara Y, Takahashi T. The prognosis of patients with gastric cancer possessing sex hormone receptors. Surg Today. 1992; 22:421-425.

44. Ryu WS, Kim JH, Jang YJ, Park SS, Um JW, Park SH, Kim SJ, Mok YJ, Kim CS. Expression of estrogen receptors in gastric cancer and their clinical significance. J Surg Oncol. 2012; 106:456-461.

45. Camargo MC, Goto Y, Zabaleta J, Morgan DR, Correa P, Rabkin CS. Sex Hormones, Hormonal Interventions, and Gastric Cancer Risk: A Meta-analysis. Cancer Epidemiol Biomarkers Prev. 2012; 21:20-38.

46. Freedman ND, Lacey JV, Hollenbeck AR, Leitzmann MF, Schatzkin A, Abnet CC. The association of menstrual and reproductive factors with upper gastrointestinal tract cancers in the NIH-AARP cohort. Cancer. 2010; 116:1572-81.

47. Nylander-Koski O, Kiviluoto T, Puolakkainen P, Kivilaakso E, Mustonen H. The Effect of Nitric Oxide, Growth Factors, and Estrogen on Gastric Cell Migration. J Surg Res. 2007; $143: 230-7$.

48. Lordick F, Mariette C, Haustermans K, Obermannová R, Arnold D, and ESMO Guidelines Committee. Oesophageal cancer: ESMO Clinical Practice Guidelines for diagnosis, treatment and follow-up. Ann Oncol. 2016; 27:v50-57.
49. Lewis C, McQuaid S, Hamilton PW, Salto-Tellez M, McArt D, James JA. Building a 'Repository of Science': the importance of integrating biobanks within molecular pat hology programmes. Eur J Cancer. 2016; 67:191-99.

50. McShane LM, Altman DG, Sauerbrei W, Taube SE, Gion M, Clark GM, and Statistics Subcommittee of NCIEORTC Working Group on Cancer Diagnostics. REporting recommendations for tumor MARKer prognostic studies (REMARK). Breast Cancer Res Treat. 2006; 100:229-235.

51. Rüdiger Siewert J, Feith $M$, Werner $M$, Stein HJ. Adenocarcinoma of the esophagogastric junction: Results of surgical therapy based on anatomical/topographic classification in 1,002 consecutive patients. Ann Surg. 2000; 232:353-361.

52. Blayney JK, Cairns L, Li G, McCabe N, Stevenson L, Peters CJ, Reid NB, Spence VJ, Chisambo C, McManus D, James J, McQuaid S, Craig S, et al, and Oesophageal Cancer Clinical and Molecular Stratification (OCCAMS) Study Group. Glucose transporter 1 expression as a marker of prognosis in oesophageal adenocarcinoma. Oncotarget. 2018; 9:18518-28. https://doi.org/10.18632/ oncotarget.24906. 